\title{
Integrated Tourism Sector in South-Eastern Asian (Mainland) Countries: A Pathway to Develop for Economic Betterment
}

\author{
Miraj Ahmed Bhuiyan ${ }^{1}$ \\ ${ }^{1}$ Wuhan University of Technology, Wuhan, China \\ Correspondence: Miraj Ahmed Bhuiyan, Wuhan University of Technology, 122 Luoshi Road, Wuhan 430070, Hubei, \\ China. E-mail: Ahmed.miraz@gmail.com
}

Received: December 26, 2014

Accepted: January 8, 2015

Online Published: January 16, 2015

doi:10.5430/ijba.v6n1p77

URL: http://dx.doi.org/10.5430/ijba.v6n1p77

\begin{abstract}
In this twenty first century, the importance of tourism sector in national economy is considered as a vital component. Though the effects of tourism in different countries are not same, still most of the countries are in a competition to attract more and more tourist. For this reason the countries, regions are taking some innovative, constructive and so on policies to attract tourist. It is not only for the betterment of the direct related tourism services components, but also indirect industries, personnel, agencies and so on.

South-Eastern Asia, a well-known tourist region is doing great in terms of number of visitors, boost up their economies through direct and indirect tourism services, facing the employment challenges and so on. Even though the region has some specific goals to meet up the expectations regarding tourism events, but still it is not enough to face the current challenges as well as attract more tourists and visitors. In this case there could be a common integrated tourism zone or sector that will help the participating countries to fulfill their expectation in recent years. In this report we will try to find out to possible economic contribution by the travel and tourism industries while the integration take place among the participating countries. We will explain the implementing pathways of integration and maintaining the whole process. Besides we will also show the benefits of this integration and possible shortcomings either.
\end{abstract}

Keywords: tourism, integration, South-eastern Asia, economic development

\section{Introduction}

Tourism is considered one of the world's largest industries in terms of gross output. As the world's growing industry, tourism offers unparalleled opportunities for economic gain in many least developed countries. Developing countries are trying to attract more and more tourist while as developed countries are enjoying this facility of earning foreign currency which is contributing a big part of their national income.

The strong growth in tourism arrivals for Asia and the Pacific, particularly the sub regions of North-East Asia, South Asia and South-East Asia is one indicator of the increased significance of tourism for developing countries. Visitors worldwide have clearly recognized the attractiveness of tourism experiences in Asian and Pacific developing countries in terms of the rich cultural heritage and natural environment. Many officials in these countries have seen that tourism can be part of their development strategies, especially in economic terms. The south eastern countries most of them are developing have a great potential in this sector. Some of the countries are doing very good towards tourism industries possibilities, but still could be better if there are some further more necessary action could be taken. For the geographical reason besides some other factors cam make this industry very much profitable for the respected countries in this region. The govt. of the countries has taken number of steps to promote the tourism but still not sufficient to create a great demand of their glorious products of unique natural and scenic beauty, oldest archeological spots, very diversified cultural attractions and so on.

\subsection{Research Objectives}

The main objectives of the research are to resolve:

- How integrated tourism can boost up respected countries economy.

- What the positive effect of integrated tourism in the region and participating countries. 
- Roadmap of implementing the integrated tourism sector.

- Maintenance of this integration.

The objective of the research was to find out the prevailing challenges and opportunities in the south-eastern Asian (mainland) region and contribution to the economic development. Tourism sector integration could be a possible way to meet the economics needs and demands while as development of these countries in the right direction. Our main objective is to focus on this regard, find out the possible way to integrate the tourism sector, implementing the idea, and also the consequences of the integration.

\subsection{Scope of the Research}

The scope of the search could be:

$\checkmark$ Guideline for developing an integrated tourism sector in the south-east Asia.

$\checkmark$ Pathways for implementing and maintaining the integration.

$\checkmark$ Suggested economics contribution by the integration of the participating countries.

Tourism is not a traditional industrial sector, and is best understood as a range of responses to a particular consumer demand. The activity of tourism creates demand for a wide range of products and services purchased by tourists and travel companies, including a range of products supplied by other industrial sectors (e.g. food \& beverage, building supplies, crafts and soft furnishings), which are not traditionally thought of as part of the tourism sector. The diversity of the industry and the high income elasticity in markets in the industrial and middle income countries make tourism an attractive option for many developing countries.

\subsection{Methodology}

In this report we have mostly used the secondary information sources. We have covered the topics related to the title from several books, journal, articles, and publications and so on. Some data we have used here were taken directly from the UN websites. (UNWTO). Some data we have used for some calculations. Besides we have personally talked with some close friends who already travelled these countries and region. I tried to explore their comments, experiences, excitements, attitudes and so on. They have already shared with me their personal point of view regarding their travel and tourism. What kinds of problem they faced, what kinds of opportunities they have discovered, what kinds of privilege they gain and so on.

Furthermore, we have some friends who are studying and working somehow related to these topics from the respective countries. They have shared their own point of view from their own experiences about their countries. They have described their opportunities, threats and so on. They have also recommended something that might be beneficial to their economic developments of the respective countries. We have also collected some secondary data from the official website of the respected countries and tourism industries. Some statistical information has been taken from these websites as well. All of cases we tried to keep the originality of the data and authenticity of the information.

\subsection{Literature Review}

There were some researches concerning tourism sectors integration. A book named 'Understanding and tourism impacts, in integrated approach" by C Michael Hall and Alan E Lew. (2008). Here they tried to show and analyze the impacts of tourism. They showed the impacts could be uni-dimensional (most of the cases), two way dimensional or multidimensional (rare). The term "cross-border integration" has multiple definitions, particularly in the context of studies on European integration (Anderson and Wever 2003; De Boe, Grasland and Healy 1999; Hansen and Serin 2007; Sohn, Reitel and Walther 2009). For cross-border regions, the integration process is fundamentally based on the existence of interactions between areas separated by an international boundary. These interactions are not limited to the economic sphere, but also concern other flows or transactions (migration, political relations, cultural exchanges, etc). Border regions are "areas whose economic and social life is directly and significantly affected by proximity to an international boundary" (Hansen, 1981). Some areas have great tourism potential. It is now somehow proved that borders have a strong effect on tourism in borderland areas. Besides Matznetter (1979) highlighted some of the connections between boundaries and tourism, and suggested a three-fold typology of spatial relationships between the two: where the boundary line is distant from tourist areas (a), where a tourist zone exists adjacent to the boundary on one side only (b), and tourist zones that extend across, or meet at the borders (c). The impacts on place, people, and environment even on economy also included the eco-tourism. Tourism collaboration and partnershipspolicy practice and sustainability also has an impact on integration process. That measured by Bill Bramwell and Bernard lane (editor, 2007) 


\section{The Tourism Sector in South-Eastern Asian Countries}

Preliminary results released by the Pacific Asia Travel Association (PATA), UNWTO Affiliate Member, showed that international visitor arrivals into Asia/Pacific destinations 1 grew by $4 \%$ year-on-year in May 2011, with the South Asia and Southeast Asia sub-regions recording particularly strong performances for the month. The first five months of 2011 showed South Asia attracted a 15\% increase in visitor arrivals. Southeast Asia came second with 12\%. Northeast Asia and the Pacific, on the other hand, only managed 3\%. Across the whole of Asia/Pacific the average growth in international visitor arrivals was 5\% for the first five months of 2011.

Southeast Asia recorded the largest arrivals gain of $16 \%$ during the month of May 2011, boosted by a $66 \%$ rebound in arrivals to Thailand, as well as by strong demand growth for Vietnam (+37\%), Myanmar (+33\%), Cambodia (+12\%) and Singapore (+11\%). International arrivals to South Asia also showed strong growth with a collective gain of $12 \%$ in May, maintaining the same pace of growth seen in 2010. All reporting destinations in this sub-region enjoyed an increase in foreign arrivals, led by Nepal $(+47 \%)$, Sri Lanka $(+39 \%)$, the Maldives $(+11 \%)$ and India $(+7 \%)$. Growth in arrivals to Northeast Asia, however, was a weak $0.6 \%$ for the month, highlighting the impact of sharply lower arrival numbers to Japan $(-50 \%)$ and the decline in the number of Japanese visitors travelling to neighboring destinations. In addition to Japan, Chinese Taipei $(-7 \%)$ and China $(-1 \%)$ also recorded falling arrivals numbers for the month. Conversely, foreign arrivals growth for Hong Kong SAR (+15\%), Macau SAR (+9\%) and Korea (ROK) $(+2 \%)$ remained positive during May 2011. Despite recent disasters and crises, South-East Asia managed to report positive annual average growth of 4.1 per cent during the period from 1996 to 2006. Cambodia and Lao People's Democratic Republic are two countries in the greater Mekong Sub region, which had strong results. For Cambodia, international tourism receipts had an average annual growth rate of 28.3 per cent and 10.8 per cent for Lao People's Democratic Republic during the ten-year period. More recently, international tourism receipts increase by 20.0 per cent between 2005 and 2006 for Cambodia. However, each of the two Mekong sub region countries accounted for less than one per cent share of international tourism receipts in Asia and the Pacific during 2005, while Cambodia's regional share was 0.6 per cent in 2006 .

The tourism receipts in Asia and the Pacific made up 20.8 percent of all international tourism receipts in 2006 compared with arrivals of 19.8 percent, suggesting that the Asian and Pacific region does slightly better on receipts from international tourism than it does on international arrivals.

\subsection{Importance of Travel and Tourism in National Economies}

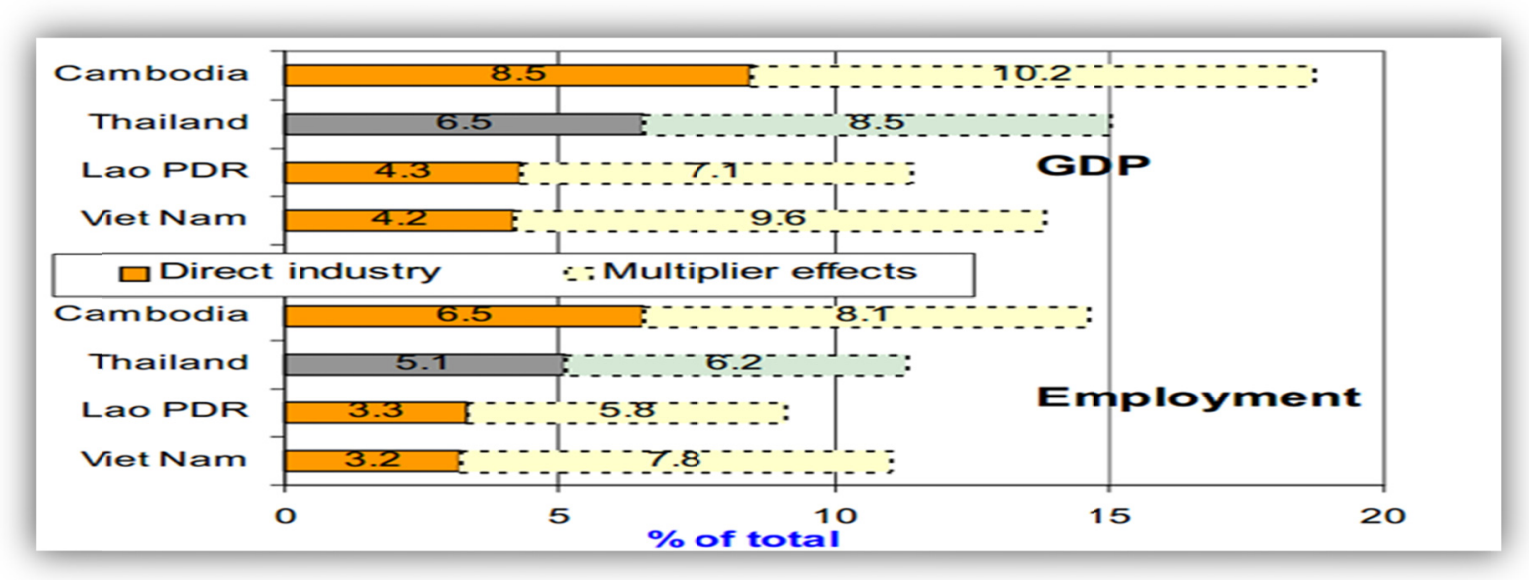

Sources: Economics and Social Commission for Asia and Pacific

From the above graph we can see the contribution of direct tourism industry to the economy (GDP) as well as with the multiplier effects. In Cambodia the direct industry contribution is 8.5 which is relatively high. If we add multiplier effects it reaches up to $10 \%$, which is really good. The situation is almost same in Vietnam with multiplier effects. Lao PDR is bit low but still in a satisfactory level. In case of Thailand the direct industry is near about 7 makes it up to $9 \%$ with inclusion of multiplier effects. 
If we go for employment situation analysis the picture is almost same. Most of the countries are above $5 \%$ with the multiplier effects. So these countries where unemployment is a big problem, tourism is playing a vital role with no doubt. But the situation could be better with good care and timely plan.

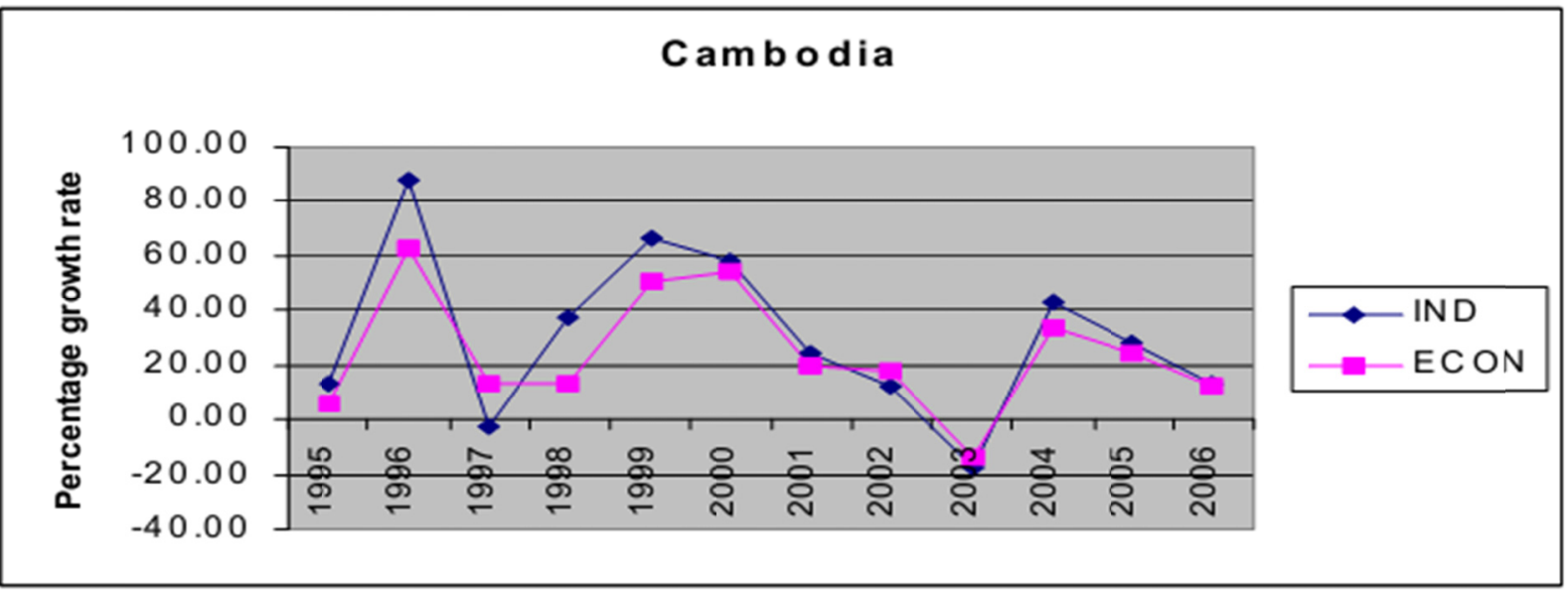

Graph 1. Percentage growth rate of tourism industries and tourism economy from (1995-2006) for Cambodia

From the above graph we can see the percentage growth rate of tourism industries and tourism economies for Cambodia for 12 years. The pink color is indicating the economy of the tourism sector while as the blue is for industries. Actually it was a mixed trend in the last decade. It went up for both of the indicator in 1996. Then sudden sharp fall down at 1997. Then rises up again and fall down again. The worst situation was 2003. It shows the negative growth. Again in 2004 it rises up dramatically but couldn't consistent for long time.

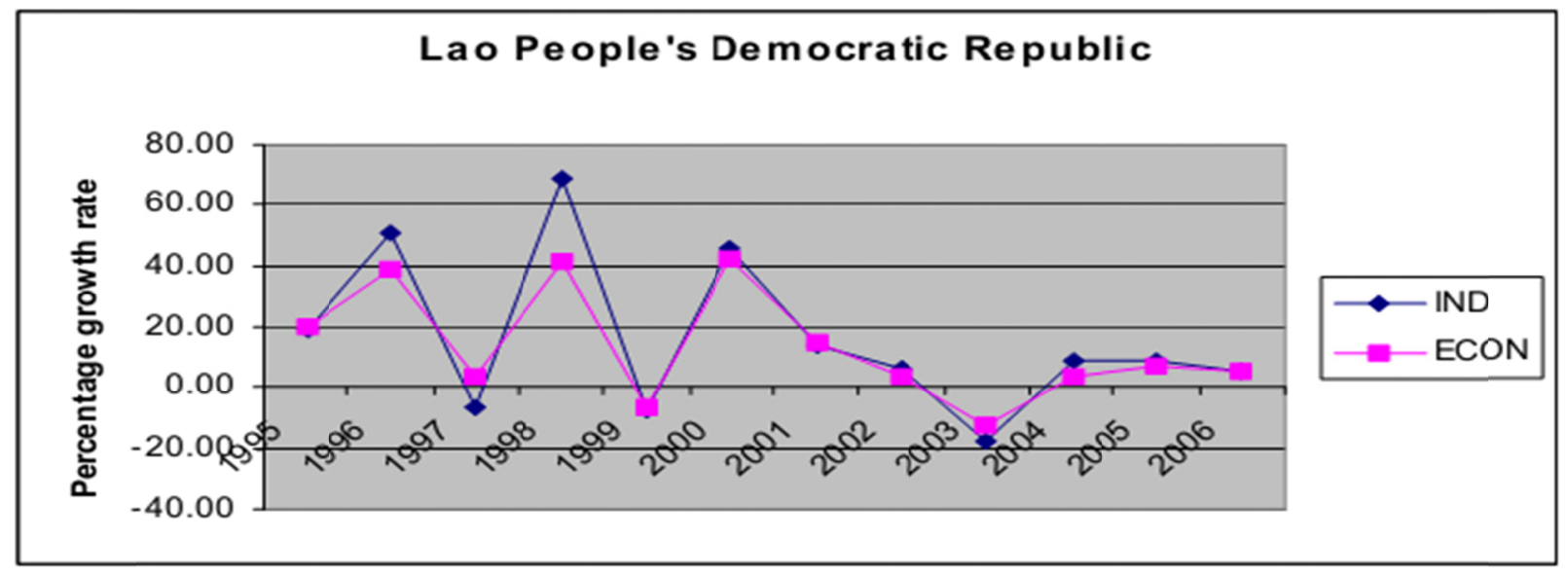

Graph 2. Percentage growth rate of tourism industries and tourism economy from (1995-2006) for LAOS

Here the color graphs are same as Cambodia. We can see the rise and fall of the trend. It goes up at 1995. Till 2004 it seems like two years same trends. Like two years goes up then go down for two years. It had a drastic fall down at 2003-2004. Then it rises up but couldn't consistence. 


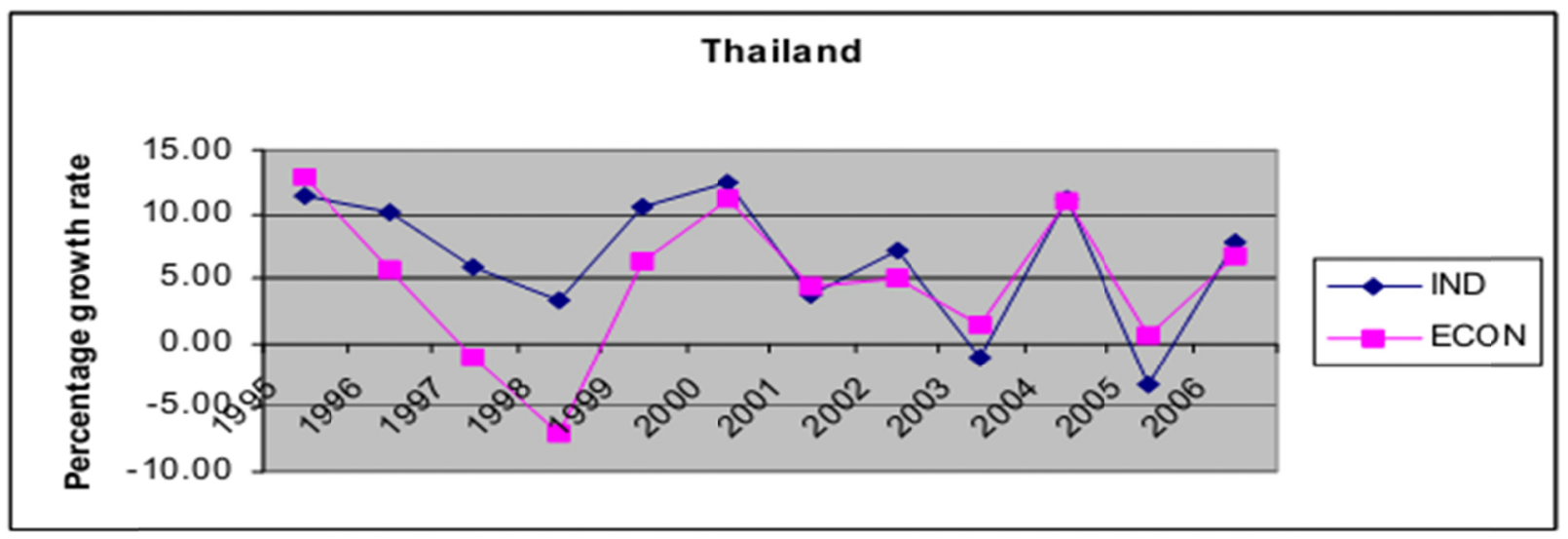

Graph 3. Percentage growth rate of tourism industries and tourism economy from (1995-2006) for Thailand

In this graph also the same color indication. From 1995 to 1999 the growth rate falls down so sharply. Then it rises up at 2000 and after that the growth rate was positive for few years. Suddenly it shows the negative growth rate and again positive at 2006 .

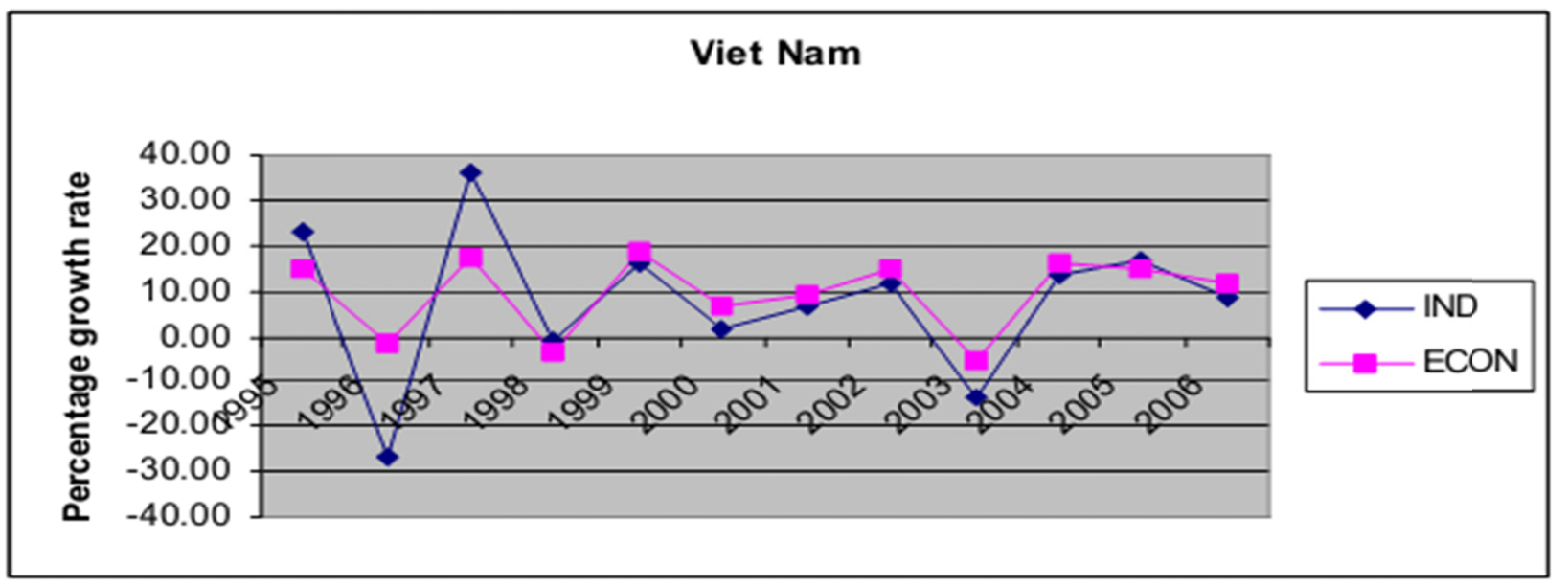

Graph 4. Percentage growth rate of tourism industries and tourism economy from (1995-2006) for Vietnam

Same color indication as above. Surprisingly the big differences at growth rate between the tourism economy and industries in 1997 and 1998. Beside this, most of the years the growth rate was positive growth rate except in 2004.

\section{Matrix Analysis for South-east Asia (Mainland)}

Let's have a look at the SWOT matrix analysis regarding tourism sector in the region. Here I tried to connect the strength and opportunities at one side along with weakness and threats in another.

\subsection{Strength-Opportunity Analysis(S-O)}

This region is already a favorable tourist spot and destination for tourists and traveler for their own attributes. The scenic spots, cheap cost, low price and so on attract tourists to visit here. This is off course a potential region for tourism. If the respective government or responsible persons take some immediate effective step, that could be possible. Sub regional cooperation is an important element for tourism development along the Mekong River. In 1995, the Governments of Cambodia, the Lao People's Democratic Republic, Thailand and Viet Nam signed the Agreement on the Cooperation for the Sustainable Development of the Mekong River Basin and identified tourism as one of the areas of cooperation.

Though this region is called the south-east Asia and there are some similarities between cultures, places and so on, but the dissimilarities are also too much that can easily attract the tourists. Now a day's more and more local or 
regional people are interested to spend their holidays out of their own respective countries. So, if there are some specific projects for specific target group that will also increase the number of potential tourist. Short vacation or holidays can be a target time. Now a day's people want to get the different cultural taste and different lifestyles even for few days. This region can be ideal place for ecotourism. These days the ecotourism is getting more popular. An integrated policy can make this possible.

This is very true that, this region is very potential for tourism industry. The respective governments can earn huge revenue from these industries. Besides the foreign currency as more and more foreigners are interested for this region. Already the numbers of foreign travelers are increasing at a good rate which can lead a top destination for travelers for local, regional and international travelers. Still this region is comparatively cheap destination for travelers compare to European or other destinations. The basic needs for the travelers are not so expensive while the good entertainment is also possible in a medium expensive way. Various kinds of accommodations, foods, transportations, dressings, shopping etc. are still not very expensive which might lead favorable destinations for the potential travelers. Well, the responsible organizations are working for the development of tourism sector of this region. But still there are lots of potential places that could be a great scenic spots and attract more tourists. For the limitation of responsible organizations or governments, sometimes it is not so easy to cope up with the situations or handle the situations. So it might be ore easy or handle the situation if the countries co-operate with each other. That will of course for mutual benefit and their own too. Asia and the Pacific, currently the world's second strongest region in terms of international tourist receipts, received a record number of tourist arrivals in 2011 (216 million international tourists - a 6\% increase on 2010 figures). According to UNWTO projections, these numbers are expected to increase by a further $4-6 \%$ during 2012 . Regionally, as well as globally, travel is a major industry which has the potential to generate millions of jobs, bring economic growth and diversification and promote regional development. As well as this, travel can be a strong contributor to poverty reduction and development in poorer parts of the world.

\subsection{Weakness-Threat Analysis (W-T)}

Although there is evidence that some tourism destinations have developed without conscious strategic and integrated planning, many of them have experienced unforeseen consequences which have led to their deterioration. Many reasons are offered for tourism planning, not least the advocacy that planning is the best way of extending the vital life-cycle of a destination by providing a means of anticipating changes, adjusting to the demands of change, and exploring new opportunities.

Organization structure and personnel system at central, provincial, district levels are not yet sufficient to meet the demand of qualitative standards. Mandate of the organizational machinery is not balanced with the growth in tourism. The knowledge and understanding of social public towards tourism is not deepened. Working style of each level are not oriented to new quality. No ownership and creative ideas. Most of staffs are waiting for orders. Inter-agency coordination between public and private is not harmonized and continuous. Each is on their own ways. Coordination among sectors concerned and local levels is not well done. Provisions and regulations are not sufficient and updated.

\section{Integrated Tourism Pathways}

Here is the proposed integrated tourism pathway for the South-East Asian countries. I have developed this flow chart on the basis is current legislation in the respective area. Also the real situation has been taken to consideration as well. 


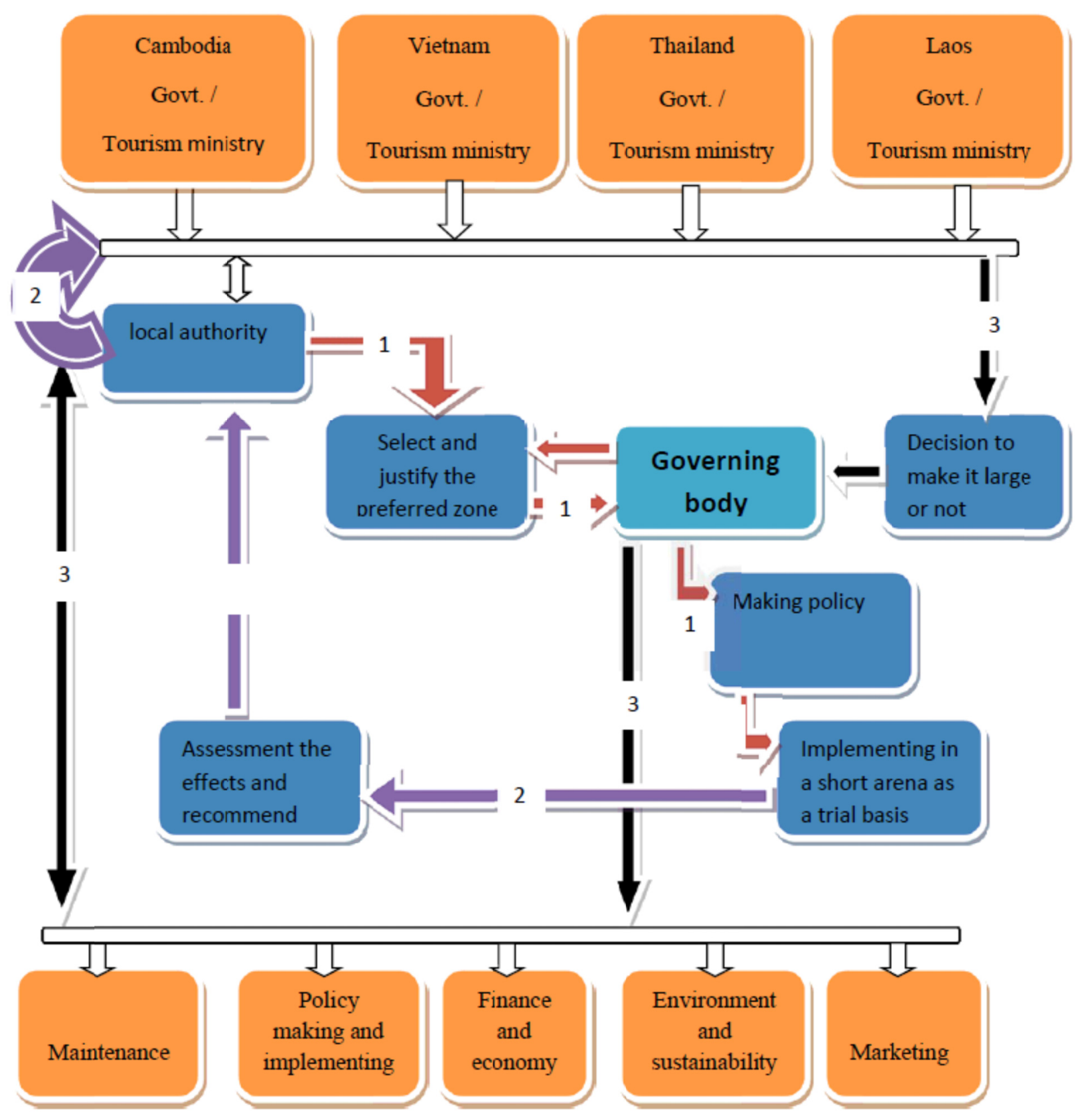

Flow chart

Here we can see the flow chart of the whole process that could be implementing in the integrated tourism sector in the region. In the top there is the govt. Of the countries or the tourism ministry who will control the local authority (LA) of these countries. The supreme power will be taken by the local authority by the recommendations of the LA. LA will select the preferred zone or area of the respected country. Then they will report to the governing body (GB) about the primary selection of the places. If the governing body (GB) accept it or have some recommendation they will report back to the local authority (LA) and local authority will report to the govt. or supreme power. After the place selection GB will make the policy and will implement in the selected areas. We can the steps that marked in the maroon color. 


\section{Step 2:}

After implement in the short areas, GB will invite the LA to find out the effects or making the next decisions. LA will investigate the effects and will report to the GB. if everything goes well and all of the parties agreed to continue or make it larger the GB will implement the rules and regulation and will finance in the preferred zone. The SP will support the GB to invest or other financial helps. If all of the parties or countries don't agree to continue or make it large they can wait or watch the effects of the other countries. The step 2 is indicated by the color light blue.

\section{Step 3:}

When the decision has taken to make the project large, GB will open some other branch and they will work as an institution. There will be several departments under the supervision of the GB. Initially it could be maintenance, marketing, economy and finance, environment and sustainability, policy making and implementing. All of these departments have to report the GB monthly and annually basis. On the base of the report GB will make and report and send to local authority on every month. Local authority will prepare a annual report and submit to the supreme power (SP). If there is something wrong within any departments, they can take help from the GB.

\section{Conclusion and Recommendation}

Tourism activity is becoming more competitive, more extensive, more complicated, and more demanding of host communities and their culture and environment. In order for the tourism enterprise in any destination area to respond positively to these challenges, it is necessary for tourism planning to be practiced in a fashion commensurate with the needs of the destination area and the nation. Integrating tourism planning into official planning - whether economic, social, welfare, environmental, infrastructure, or cultural - has been slow, and remains unusual. The ideal model would be a national/regional/local comprehensive planning system in which tourism is an integral component. This model is rare, which is not surprising, as the various component strategies within tourism are seldom integrated. The important aims at two levels are for the various interests, requirements and needs to be fused together into a composite, integrated strategic tourism plan for tourism to be planned with the intention of being fused into the social and economic life of a region and its communities.

Tourism planning has been beset by a number of new challenges. Among these new challenges could be a response to the threat of environmental deterioration along with recognition that tourism can be synergized with protected areas. The principles of sustainable development with Special interest tourism, Ecotourism, Conservation and resource protection, Destination identity and Public sector and private sector co-operation is also very important for such types of tourism integration. The danger could be that tourism will become over-planned. Rather than act as a constraint, the new approaches to tourism planning may be Foster new planning concepts and processes, be open-ended as well. The important characteristics of integrated tourism planning might be a good decision-making structure designed to link tourism with other sectors of economic and infrastructure development along with An approach which is strategic and goal-oriented rather than being re-active and preventative. Besides, A structure which can accommodate inputs and influences from the tourism industry, other sectors of government, and the affected community and A process which is purposive and deliberate, but which is also flexible to adjust to changing circumstances with A process which is guided by principles of good management is also considerable. It is important in designing a planning process to adopt a procedure that is understandable, defensible, where decisions can be traced and where the value judgments inherent in protected area planning are made explicit. Most of all, it is essential that all stakeholders are appropriately involved in the process. Making management decisions about tourism in protected areas is not easy; it involves not only protected area managers but also affected citizens, including the local public, visitors, private operators and scientists. An efficient transport infrastructure has been considered as a key component that directly influences the competitiveness of a country's travel and tourism industry. For countries in Asia and the Pacific, this includes an accessible, high-quality air traffic network, established tourism infrastructure, and a well-developed multi-modal ground transportation network. As suggested by WEF, the importance of various factors and variables that make up travel and tourism competitiveness is likely to vary depending on each country's stage of development. Determining the dynamics of building up infrastructure as well as the air and ground transport network in different development and geographical contexts could be based on systematically comparing economies in various stages of development, identifying specific key success factors and learning lessons that can be applied for particular groups of countries

\subsection{Towards Collaborative Travel}

The next decade and beyond will see a qualitative shift in the travel experience. The future of travel is likely to be shaped by technological innovations which reduce stress, uncertainty and chaos. At every step of the journey, travel 
will be enhanced by greater and more fluid interaction with other travelers and travel providers. But all this is only possible by new technologies and innovations which will underpin and enable this greater fluidity and interaction to become a reality.

\subsection{The Experience of Being Elsewhere}

Our experience of a place will increasingly be seen through the lens of other people who are simultaneously there with us or have been there previously. Travel will become more about depth rather than breadth of experience, as we come to realize that all places are layered according to their history and culture of who is there and who else has been there previously. Furthermore, as the boundary between travel for leisure and travel for work will blur, this collaborative experience of travel will impact on business travel as well. Continued emphasis on work-life balance and wellbeing at work may mean employers increasingly allow people to take time off either side of a business trip. The business traveler could, in other words, become the business tourist.

\subsection{Information Exchange}

Peer groups, the internet and experts will form an information eco-system which will be more collaborative than the one-to-one transactional relationships that predominate today. As technologies make it easier for people to tag and review all aspects of travel experience, travelers will be influenced by peer groups much more. Moreover, as data on payments is shared and integrated, it will leave a trail of digital breadcrumbs, tracing where we've been and what we've done. Travelers will be able to browse and learn from this layer of information, and for the travel provider, digital breadcrumbs are likely to become an important customer-profiling tool. There will also be an opportunity for travel providers to participate in the wider information eco-system. Helping users navigate their way through this will be one of the main ways travel providers; particularly travel agents can add value. Travel providers will have a big role to play in this new age of collaborative travel. However, they will need to shift focus from satisfying the needs and wants of the traveler as an individual, to providing the environment for networks and flows of travelers as a group to move and flourish.

\subsection{Easy Visa Policy or Single Visa Policy}

The participating countries could be come to an agreement that will let them make the visa policy much easier or even single visa policy for preferred zone. That will not only encourage the neighboring countries tourist but also the regional as well as international tourist to pay a visit in the preferred zone. Ultimately it will help to boost up the concerning countries. There are lots of international travelers avoid to travel some countries just because of visa complicacy.

\subsection{Special Zone / Preferred Tourism Area}

Special zone or preferred area should be making under the policy of the local government and the governing body. That will simplify the integration and will ease to control the whole process. It will also help to reduce the cost investment and marketing.

\subsection{Special Transportation Route and System}

Easy and convenient route can be built for transportation. At the same time the natural attraction could be a factor while thinking to make a new route or re-building the old route. Special transportation system should be formed at least within the zone. There are various kinds of transportation that could be facilitated the friendly and attractive offer for the travelers. Not only for the domestic or regional, international tourist facility should be intended in the transportation mega plan.

\subsection{Single/Common Currency}

There should a single currency in the preferred zone so that the visitor can get rid of the currency converting troubles. It will make their journey more comfortable and willing to spend more while travelling. Another alternative option could be availability of currency converting agencies or institutions in the respected areas.

\subsection{Unique/Common Visa}

Unique visa can be offered for the preferred zone. This visa could be for single or even multiple entrances in the respected areas. Many travelers are facing the problems for getting visas or finding the difficulties to get the adequate information regarding entry policy. Such kinds of drawbacks could be minimized by introducing the unique visa policy for the respected countries preferred area. 


\subsection{Common Tourist Guide Facility}

Some of the tourists don't like to change the guides along the whole journey. So maybe there could be some trained tourist guide who can be with the team or even some individuals during the whole journey. These guides should be well trained up according to the respected countries history, political situation, culture and so on. This can helps the travelers to have a smooth and wonderful travel.

\subsection{Improved Accommodation Facility}

Well even there are some good hotels and residence places in these countries, but it still not enough. Since the plan for preferred zone is to attract more and more tourists, obviously there should have a nice accommodation for them. It should include several classes from lower to upper high.

\subsection{Assurance of High Security}

Security is a very important issue these days. All sort of people are concern of the security for their travelling concern. Last few decades the lack of security affected much for tourism industry. Govt. Of the respected country should support the governing body to ensure the security of the preferred place as well the whole region.

\section{References}

Ashley, C., Debrine, P., Lehr, A., \& Wilde, H. (2007). The Role of Tourism Sector in Expanding Economic Opportunity. Harverd University Press, School of Governemence.

Chon, K.S. (ed.) (2000). Tourism in Southeast Asia- A New Direction. Haworth Hospitality Press, Bahimghamton NY.

Cochrane, J. (ed.) (2008). Asian Tourism: Growth and Change. Linarce House Jordan Hill, Oxford UK.

Hall, C.M., \& Page, S. (2000). Tourism in South and South-east Asia: Issues and Cases. Linarce House, Jordan Hall Oxford.

Hitchcock, M., King, V. C.T., \& Parnwell, M. (eds.) (2008). Tourism in Southeast Asisa: Challenges and New Directions. NIAS Press, Denmark.

Kerr, W. R. (2003). Tourism Public Policy and Strategic Management of Failure. The Boulevard Langford Lane, Oxford UK.

Pham, S., Emmons, R., Eveland, J., \& Liu, J. L. (2009). Frommer's Southeast Asia. Wiley Hoboken New Jersey, USA.

Retrieved from http://blogs.ft.com/beyond-brics/2010/06/15/thailands-tourism-industry

Retrieved from http://www.nuwireinvestor.com/articles/thailands-tourism

Retrieved from http://www.tourismlaos.org/userfiles/2009\%20Statistical\%20Report

Shaw, G., \& Williams, A. M. (2004). Tourism and Tourism Spaces. London UK.

Teo, P., Chang, T.C., \& Ho, K.C. (2001). Interconnected Worlds- Tourism in Southeasy Asia. Boulevard, Langbard Lane UK. 